\title{
Editorial
}

Neuro epidemiology

\section{Measuring the Prevalence of Stroke}

\author{
Matthew F. Giles Peter M. Rothwell \\ Stroke Prevention Research Unit, Department of Clinical Neurology, University of Oxford, Radcliffe Infirmary, \\ Oxford, UK
}

Stroke is common and causes considerable morbidity and mortality. Given the strong association between stroke incidence and increasing age, the ageing of the population means that the prevalence of stroke could well be rising and so accurate and up-to-date measurement is important for the planning and delivery of effective health (and social) care provision. The community survey reported by Jungehulsing et al. [1] is therefore timely and important.

In a postal survey of 75,720 households containing at least one person over 50 years old in Berlin, with a response rate of $37.5 \%$, they estimated the prevalence of a physician-diagnosed stroke to be $4.5 \%$ and the rate of prior stroke symptoms to be $2.7-5.0 \%$ (depending on the symptom). Combining the rates of reported stroke history with previous stroke symptoms, the prevalence of stroke was estimated to be $7.6 \%$, which is within the range reported in previous studies from other countries [2]. Higher stroke prevalence was associated with increasing age, male sex, non-German nationality, living alone, lower educational achievement and a positive family history of stroke.

The attempt to identify stroke events that had not been reported to, or diagnosed by, a doctor was an important aspect of the study. Subjects were questioned about previous stroke symptoms using an adapted version of the Stroke Symptom Questionnaire, with identification of previously undiagnosed stroke based on a positive response to questions about speech difficulty or visual im- pairment. Although this combination of questions was chosen as having the optimal sensitivity and specificity in a validation cohort of 384 elderly Germans [3], and responses were screened by neurologists, the accuracy of the adapted questionnaire is difficult to judge. The original Stroke Symptom Questionnaire also included questions about limb weakness, facial weakness and sensory disturbance and included photographs to illustrate facial weakness and the visual disturbance most commonly associated with stroke. The slimmed-down version used by Jungehulsing et al. [1] would very probably have somewhat reduced sensitivity. Moreover, given the fact that many strokes are relatively mild and recover within a few days or weeks, a significant proportion of elderly individuals are likely to have forgotten about stroke symptoms, and even physician-diagnosed strokes, that occurred many years previously. However, the consequent underestimation of stroke prevalence is likely to be compensated, or possibly reversed, by overdiagnosis of strokelike symptoms that had in fact been due to some other cause.

Overall, therefore, the estimate of prevalence was probably reasonably accurate in the $37.5 \%$ of the households that responded. Moreover, any concern about possible overdiagnosis due to incorrect interpretation of the very limited clinical data available should be tempered by the fact that minor stroke-like symptoms appear to be informative irrespective of the correct diagnosis. In the REGARDS study, individuals without a previous physi-

\section{KARGER}

Fax +4161306 1234

E-Mail karger@karger.ch

www.karger.com
(C) 2008 S. Karger AG, Base

0251-5350/08/0304-0205\$24.50/0

Accessible online at:

www.karger.com/ned
Dr. Matthew F. Giles

Stroke Prevention Research Unit, Department of Clinical Neurology

University of Oxford, Radcliffe Infirmary, Woodstock Road

Oxford OX2 6HA (UK)

Tel. +44 1865617 158, Fax +44 1865617 160,E-Mail matthew.giles@clneuro.ox.ac.uk 
cian-diagnosed stroke who reported stroke-like symptoms were more likely to have vascular risk factors and to have poor physical and mental function than those who were symptom free $[4,5]$. It could be that these individuals have 'silent' brain infarction, although no data are available on their prognosis.

The authors discuss the various biases that might have resulted from their incomplete picture of the population. Although a $37.5 \%$ response rate is high in comparison with previous similar studies, the stroke prevalence among the $62.5 \%$ who did not respond is, of course, uncertain. Previous severe stroke, cognitive impairment or other stroke-associated conditions could have led to a failure to respond, and hospital inpatients and those in institutional care were not surveyed, possibly leading to an underestimation of the true prevalence. On the other hand, those with previous stroke may be more likely to be sufficiently interested to respond, leading to bias in the opposite direction. The only data available to the investigators on non-responders were age and sex which were similar to responders, although the proportion of nonGerman responders was lower than that in the general population.
Despite the mostly inevitable limitations of a study such as this, the observation that stroke had apparently affected 1 in 20 households is an important one. The high prevalence of apparent stroke symptoms in subjects without a physician-diagnosed stroke is also striking. However, given that people who had had a disabling stroke would almost always seek medical attention and receive and recall the correct diagnosis, the non-reported or nondiagnosed strokes are likely to have been fairly mild. Nevertheless, since similar high rates of unreported symptoms have been described in studies using different sampling methods, including telephone surveys [4-6] and face-to-face follow-up in clinical trials [7], and given the recent evidence of the high risk of major stroke in the days and weeks after transient ischaemic attack and minor stroke [8], the fact that many people in the community do not report stroke-like symptoms is worrying. The findings of this study again highlight the need for greater public education about how to recognise a transient ischaemic attack or stroke and what action to take.

\section{References}

1 Jungehulsing GJ, Muller-Nordhorn J, Nolte $\mathrm{CH}$, Roll S, Rossnagel K, Reich A, Wagner A, Einhaupl KM, Willich SN, Villringer A: Prevalence of stroke and stroke symptoms: a population-based survey of 28,090 participants. Neuroepidemiology 2008;30:51-57.

2 Feigin VL, Lawes CM, Bennett DA, Anderson CS: Stroke epidemiology: a review of population-based studies of incidence, prevalence, and case-fatality in the late 20th century. Lancet Neurol 2003;2:43-53.

3 Berger K, Hense HW, Rothdach A, Weltermann B, Keil U: A single question about prior stroke versus a stroke questionnaire to assess stroke prevalence in populations. Neuroepidemiology 2000;19:245-257.
4 Howard VJ, McClure LA, Meschia JF, Pulley L, Orr SC, Friday GH: High prevalence of stroke symptoms among persons without a diagnosis of stroke or transient ischemic attack in a general population: the Reasons for Geographic and Racial Differences in Stroke (REGARDS) study. Arch Intern Med 2006; 166:1952-1958.

5 Howard G, Safford MM, Meschia JF, Moy CS, Howard VJ, Pulley L, Gomez CR, Crowther M: Stroke symptoms in individuals reporting no prior stroke or transient ischemic attack are associated with a decrease in indices of mental and physical functioning. Stroke 2007;38:2446-2452.
6 Johnston SC, Fayad PB, Gorelick PB, Hanley DF, Shwayder P, van Husen D, Weiskopf T: Prevalence and knowledge of transient ischemic attack among US adults. Neurology 2003;60:1429-1434.

7 Castaldo JE, Nelson JJ, Reed JF 3rd, Longenecker JE, Toole JF: The delay in reporting symptoms of carotid artery stenosis in an atrisk population. The Asymptomatic Carotid Atherosclerosis Study experience: a statement of concern regarding watchful waiting. Arch Neurol 1997;54:1267-1271.

8 Giles MF, Rothwell PM: Risk of stroke early after transient ischaemic attack: a systematic review and meta-analysis. Lancet Neurol 2007;6:1063-1072. 